\title{
Bicultural Iranians Political Tendency: In Between Two Cultures
}

\author{
Kaviani $\mathbf{H}^{1^{*}}$, Kinman $\mathbf{G}^{1}$ and Salavat $\mathbf{M}^{2}$
}

${ }^{1}$ Department of Psychology, University of Bedfordshire, Luton, UK

${ }^{2}$ Psychological Counselling Office, Javad-Kargar St, Shariati Av, Tehran, Iran

*Corresponding author: Dr Hossein Kaviani, Department of Psychology, University of Bedfordshire, Luton, UK, Tel: +44 (0)1582 743765; E-mail: hossein.kaviani@beds.ac.uk

Rec date: May 23, 2017; Acc date: May 30, 2017; Pub date: June 10, 2017

Copyright: (C) 2017 Kaviani H, et al. This is an open-access article distributed under the terms of the Creative Commons Attribution License, which permits unrestricted use, distribution, and reproduction in any medium, provided the original author and source are credited.

\begin{abstract}
The present study aimed to examine differences in a range of psychosocial variables and political tendencies across three groups, namely Iranian new-comers (who have lived in the UK for less than two years), bicultural Iranians (born and raised in the UK or raised in the UK since they were under 10 years old), and UK citizens (bicultural participants were excluded). The target variables measured in the present study consisted of empathy, Theory of Mind (ToM), flexibility, suggestibility, openness to experiences, normative identity style, interpersonal trust, pro-social behaviour, egalitarian sex role, authoritarianism and adherence to democracy. A series of MANOVAs revealed significant main group effects for most of variables. The results of post hoc and polynomial tests yield an incremental linear trend on empathy, theory of mind, interpersonal trust, openness, pro-social behaviour and adherence to democratic values for groups ordered as Iranian new comers, bicultural and British; a decreasing trend was also observed on normative identity style, suggestibility, and authoritarianism. Thse between-two cultures' findings of bicultural group might be explained by learning through political socialization. This provides support for the fact that being raised in a distinct cultural setting can have a vivid impact on people's psychological characteristics and socio-political tendency.
\end{abstract}

Keywords: Democratic values; Authoritarianism; Socialization; Political tendency; Bicultural

\section{Introduction}

Plato: 'politics needs to be understood (and undertaken) in the light of human nature and human development' [1].

There is evidence $[2,3]$ that suggest a direct association (either direct or reverse) between adherence to democratic values and individual difference, for instance empathy, theory of mind, authoritarianism, interpersonal trust, normative identity style, openness and suggestibility.

Early research conducted by Adorno, Frenkel-Brunswik, Levinson and Sanford [4] emphasized a potential link between personality characteristics and people's political tendency. Accordingly, personality characteristics would play a part in internalizing ideas which are compatible or in repelling ideas which are incompatible with the individual psychological needs. Greenstein [5] drew on two personality types, namely authoritarian and democratic characters, and explained how each type is associated with behaviour in a context. He went on to discuss the role of political socialization in the development of these personality types. More recently, evidence has been found for environmental influence on personality traits [6]. From the social learning perspective [7], it can be assumed that political tendency and behaviour are constructed through a process of social learning. There are interacting socialization agents such as family [8,9], peers [10], school [11], and cultural values [12] that are thought to have an impact on the development of civic attitudes (including support for democratic values and tolerance). Other researchers have found that early and later life experiences and knowledge can influence people's political tendency and behaviour [12] examined the role of life experiences within the family, the school, and the wider social context in shaping personal mind-sets such as political trust in adulthood. It can be concluded that political attitudes develop over life course because of accumulated experiences and attained knowledge.

The underlying assumption in the present study is whether a range of individual differences that have previously been found to underpin people's socio-political attitude and behaviour are influenced by the cultural setting in which they are living. In this study, we aim to shed light on this issue from a cultural perceptive. This study builds on previous research conducted by the authors [3] who tested a sample of Iranian and UK students providing data on the preliminary psychometric properties as well as the applicability and feasibility of a series of measurements which are potentially relevant to socio-political tendencies; some of the measurements are employed in the present study. This study builds on the previous research by examining bicultural (Eastern-Western) differences among three groups relating to key individual difference variables. Participants are Iranian first generation (who lived most of their life in their country of origin), Iranian second generation (who were born or lived most of their lives in the UK) and a British sample. It is assumed that there exists a linear trend (incremental or decreasing) respectively between Iranian first generation, Iranian second generation and British sample on measured variables. This would imply that being raised in a new cultural setting can influence people's attitude and political tendency. The target variables which were measures in the present study encompassed empathy, theory of mind (ToM), flexibility, suggestibility, openness, normative identity style, interpersonal trust, pro-social behaviour, egalitarian sex role, authoritarianism and adherence to democracy.

We are, moreover, interested to gauge the gender effect, as some of the proposed variables in this study proved to be gender sensitive eg, adherence to democracy $[13,14]$ empathy [15] suggestibility [16] and 
egalitarian sex role [17]. We also aim to examine the inter-correlations of the variables.

\section{Method}

\section{Participants and procedure}

Volunteers were recruited from a convenience sample and allocated into one of three groups:

- Iranian new-comers: Those who have been in the UK as students for less than two years. This group was regarded as a sample with an Eastern cultural background.

- Bicultural sample: Students with an Iranian background born and raised in the UK or raised in the UK since they were less than 10 years old. They were excluded from the study if one of the parents were not Iranian. This group was regarded as bicultural, as they simultaneously belong to two cultures through their heritage and their place of residence.

- British sample: Students who were born and raised in the UK. Those with any bicultural background were excluded. This group was deemed to be a sample with Western cultural background.

A trained research assistant invited volunteers to fill in questionnaires and scales, via Iranian cultural and student associations in England. The British sample was recruited through announcements in different academic institutions including under- and post-graduate classrooms at a University in the UK. The number of participants in each group were: Iranian group $=187$; bicultural group $=132$ and British group $=28$. The data of 38 participants in Iranian newcomers, 21 in bicultural group and 12 from British sample were eliminated from analysis due to incomplete response to items of the measures. The final sample sizes for Iranian newcomers, bicultural and British groups were 149 (response rate=79.6\%), 111 (response rate=84.1\%) and 116 (response rate $=90.1 \%$ ) respectively.

The research project was approved by the ethics committee at the University. A paper-based method was used to collect data. Participants read and signed a fully informed consent. They were reassured that their personal details and questionnaire data would be kept confidential and they would be free to withdraw from this study at any time. All questionnaires were anonymised.

A previous study provided valid psychometric properties of the scales and questionnaires used in this study. Utilising indices of validity (based on convergent or divergent validity) and reliability (internal consistency), the measures appeared to demonstrate sufficient validity to be utilised in this study. According to item analysis and factor loading, some of the items in each measure were excluded and the remaining items were used in the present study [3].

\section{Measures}

Empathy: To measure empathy (one's ability to understand others' emotions), a 10-item questionnaire derived from Toronto Empathy Questionnaire [15] was used. One example of items is "I have tender, concerned feelings for people less fortunate than me". Items are rated on a scale ranging from 0 (never) to 4 (always).

Flexibility (From HEXACO Personality Inventory [18]): Flexibility has 8 items such as "When people tell me that I'm wrong, my first reaction is to argue with them." Each item is rated on a 5-point scale from strongly disagree (1) to strongly agree (5). The scale refers to one's readiness to change specially in social decision making.

Theory of mind (ToM): ToM refers to one's ability to understand others' thoughts and viewpoint and was measured with 6 items derived from Perspective Taking (PT sub-scale from IRI; Davis, 1983(19). An example is "When I am upset at someone, I usually try to 'put myself in his shoes' for a while". Rating scale for each item is based on a 5-point scale ranging from 0 ('does not describe me well') to 4 ('describes me well') [19].

Openness to experience: It consists of 12 items derived from NeoPI-R [20]. Items measure willingness to experience new activities, consider new, perhaps unconventional ideas, and measure belief in pluralistic values. An example is "I have a lot of intellectual curiosities". A 5-point scale from 'strongly disagree' (1) to 'strongly agree' (5) was used to rate each item. The Openness scale has been previously translated to Farsi and validated in an Iranian sample [21].

Normative identity style: Derived from Normative Identity Style [22], the NIS used in this research, comprised of 7 items (e.g., "I automatically adopt and follow the values I was brought up with."). The items are intended to assess how people see themselves in harmony with expectations of significant others and referent groups in terms of collective ideas pertaining religion, family and nationality. Each item is rated from 1 ('not at all like me') to 5 ('very much like me').

Suggestibility: It consists of 7 items of Multidimensional Iowa Suggestibility Scale [16] (e.g., "I am easily influenced by other people's opinions"). Each item is rated on a 5-point scale from 1 ("not at all or very slightly') to 5 ('a lot'). Suggestibility as a personality trait is defined to be a general tendency to accept and internalise messages uncritically.

Interpersonal trust: It has 8 items (e.g., "In dealing with strangers one is better off to be cautious until they have provided evidence that they are trustworthy."), derived from International Trust Scale [23]. It detects the extent to which one trusts others in social context. Respondents are instructed to rate each item using a 5-point scale ranging from 1 ('strongly disagree') to 5 ('strongly agree').

Prosocial behaviour scale: Derived from Altruism Scale [24], Prosocial Behaviour Scale consists of 10 items. A sample item is: "I have donated blood." A 5-point rating scale was used by respondents to evaluate their engagement in prosocial behaviours based on categories 'Never' (1), 'Once' (2), 'More Than Once' (3), 'Often' (4) and 'Very Often' (5).

Gender role equality scale: Based on 10 items of Egalitarian Sex Role Attitude [17], this scale measures beliefs and attitudes on how equal people see men and women. A sample item is: "Domestic chores should be shared between husband and wife." The answer ranges from 1 ('strongly disagree') to 5 ('strongly agree'). This scale first was developed in Japan and then translated and used in North America.

Authoritarianism scale: This scale consists of 9 items derived from Right Wing Authoritarianism [25]. The items are intended measure authoritarian submissiveness, aggression, and conventionalism (e.g., "our country needs a powerful leader, to destroy the radical and immoral currents prevailing in our society today"). Response options range from 1 ('strongly disagree') to 4 ('strongly agree').

Adherence to democratic values: To assess people's tendency to support democracy and commitment to democracy, 9 items of the scale Support for Democratic Values [2] were used. A 4-point rating 
Citation: Kaviani H, Kinman G and Salavat M (2017) Bicultural Iranians Political Tendency: In Between Two Cultures. J Socialomics 6: 206. doi:

Page 3 of 6

scale from 1 ('strongly disagree') to 4 ('strongly agree') was used to rate each item. A sample item is "Democracy may have its problems, but it's better than other forms of government").

\section{Data Analysis}

To statistically analyse the data, SPSS for Window, version 21 was utilised. To detect group, gender and the interaction effects, a series of three (Group: Iranian, bicultural, British) x two (Gender: male, female) MANOVAs were performed on the measured variables separately followed by post hoc Bonferroni tests. In addition, a series of polynomial contrast tests was conducted to examine linear trend for groups (ordered Iranian new comers, bicultural, and British) on each variable. If there appeared a gender main effect, an independent $t$-test was conducted to detect further. Pearson correlation was used to detect potential inter-correlations between variables.

\section{Results}

\section{Demographics}

Table 1 depicts demographic variations of Iranian, bicultural and British samples. Data shows the proportion of men and women are comparable across groups. Iranian group are slightly older than bicultural group; and bicultural group slightly older than British group. In terms of education, Iranian sample are at a post-graduate level than the other two groups.

\begin{tabular}{|c|c|c|c|c|}
\hline Variables & Iranian & Bicultural & British & Total \\
\hline Sample size (\%) & $149(39.7)$ & $116(30.8)$ & $111(29.5)$ & 376 \\
\hline \multicolumn{5}{|c|}{ Gender } \\
\hline Men (\%) & $62(41.6)$ & $48(41.3)$ & $46(41.4)$ & 156 \\
\hline Women (\%) & $87(58.4)$ & $68(58.7)$ & $65(58.6)$ & 220 \\
\hline \multicolumn{5}{|c|}{ Age } \\
\hline Mean (SD) & $27.26(10.33)$ & $26.9(9.5)$ & $24.8(6.5)$ & $26.1(9.1)$ \\
\hline \multicolumn{5}{|c|}{ Education } \\
\hline PG (\%) & $83(55.1)$ & $43(37.1)$ & $28(25.2)$ & $154(40.9)$ \\
\hline UG (\%) & $43(28.8)$ & $44(37.9)$ & $72(64.8)$ & $159(42.2)$ \\
\hline College/G.C.S. Es (\%) & $23(16.1)$ & $29(25.0)$ & $11(10.0)$ & $63(16.9)$ \\
\hline
\end{tabular}

Table 1: Demographic variations in Iranian, bicultural and British samples.

\section{Group differences: A linear trend}

Table 2 summarizes MANOVA outputs. Only a significant gender effect was found on empathy $(\mathrm{F} 2,369=369, \mathrm{P}<0.001)$ showing that women (Mean $=26.44)$ scored higher on empathy than men (Mean $=24.60)(\mathrm{t} 373=4.39, \mathrm{p}<0.001)$.

Apart from the variable flexibility, significant main group effects were found for all other variables. The result of post hoc and polynomial test yields an incremental linear trend on empathy, theory of mind, interpersonal trust, openness, prosocial behaviour and adherence to democratic values for groups ordered as Iranian new comers, bicultural and British; a decreasing trend was also observed on normative identity style, suggestibility, and authoritarianism. This shows that bicultural group performance on the questionnaires was mostly between scores obtained by Iranian new comers and the British.

\begin{tabular}{|c|c|c|c|c|c|c|c|}
\hline & Iranian & Bicultural & British & F-value & P-value & $\begin{array}{l}\text { Post-hoc } \\
\text { Bonferroni }\end{array}$ & Linear effect \\
\hline Empathy & $23.94(3.57)$ & $26.66(2.88)$ & $27.14(4.84)$ & 25.86 & 0.001 & $\begin{array}{l}1-2: p<0.001 \\
1-3: p<0.001 \\
2-3: \text { NS }\end{array}$ & $\begin{array}{l}C E^{*}=1.94 \\
p<0.001\end{array}$ \\
\hline Theory of mind & $13.31(3.16)$ & $15.87(1.91)$ & $15.19(4.22)$ & 17.63 & 0.001 & $\begin{array}{l}1-2: p<0.001 \\
1-3: p<0.001 \\
2-3: \text { NS }\end{array}$ & $\begin{array}{l}C E=1.18 \\
p<0.001\end{array}$ \\
\hline Flexibility & $22.44(4.39)$ & $23.42(3.74)$ & $23.58(5.37)$ & 1.28 & NS & $\begin{array}{l}1-2: N S \\
1-3: N S\end{array}$ & $\begin{array}{l}C E=.89 \\
p<0.05\end{array}$ \\
\hline
\end{tabular}


Citation: Kaviani H, Kinman G and Salavat M (2017) Bicultural Iranians Political Tendency: In Between Two Cultures. J Socialomics 6: 206. doi:

Page 4 of 6

\begin{tabular}{|c|c|c|c|c|c|c|c|}
\hline & & & & & & 2-3: NS & \\
\hline Egalitarian sex role & 28.09 (3.99) & $31.10(3.15)$ & $31.11(4.53)$ & 23.26 & 0.001 & $\begin{array}{l}1-2: p<0.001 \\
1-3: p<0.001 \\
2-3: \text { NS }\end{array}$ & $\begin{array}{l}C E=2.04 \\
p<.001\end{array}$ \\
\hline Normative identity style & $22.24(2.13)$ & $18.26(3.48)$ & $18.79(5.44)$ & 40 & 0.001 & $\begin{array}{l}1-2: p<0.001 \\
1-3: p<0.001 \\
2-3: \text { NS }\end{array}$ & $\begin{array}{l}C E=-2.55 \\
p<0.001\end{array}$ \\
\hline Interpersonal Trust & $15.66(2.74)$ & $16.21(2.51)$ & $17.82(2.54)$ & 17.05 & 0.001 & $\begin{array}{l}1-2: \text { NS } \\
1-3: p<0.001 \\
2-3: p<0.001\end{array}$ & $\begin{array}{l}C E=1.54 \\
p<.001\end{array}$ \\
\hline Openness & $31.59(5.90)$ & $34.23(3.45)$ & $39.99(6.45)$ & 64.8 & 0.001 & $\begin{array}{l}1-2: p<0.001 \\
1-3: p<0.001 \\
2-3: p<0.001\end{array}$ & $\begin{array}{l}C E=6.11 \\
p<0.001\end{array}$ \\
\hline Suggestibility & $24.87(2.25)$ & $23.44(1.81)$ & $20.85(5.34)$ & 44.29 & 0.001 & $\begin{array}{l}1-2: p<0.005 \\
1-3: p<0.001 \\
2-3: p<0.001\end{array}$ & $\begin{array}{l}C E=-3.22 \\
p<0.001\end{array}$ \\
\hline Prosocial behaviour & $23.53(2.84)$ & $24.69(2.90)$ & $27.12(7.00)$ & 18.58 & 0.001 & $\begin{array}{l}1-2: \text { NS } \\
1-3: p<0.001 \\
2-3: p<0.001\end{array}$ & $\begin{array}{l}C E=2.57 \\
p<0.001\end{array}$ \\
\hline Authoritarianism & $22.10(3.07)$ & $20.02(2.01)$ & $20.37(4.36)$ & 15.68 & 0.001 & $\begin{array}{l}1-2: p<0.001 \\
1-3: \text { NS } \\
2-3: p<0.001\end{array}$ & $\begin{array}{l}C E=-1.52 \\
p<0.001\end{array}$ \\
\hline Democratic values & $20.17(2.35)$ & $22.34(2.53)$ & $26.83(3.75)$ & 168.82 & 0.001 & $\begin{array}{l}1-2: p<0.001 \\
1-3: p<0.001 \\
2-3: p<0.001\end{array}$ & $\begin{array}{l}C E=5.04 \\
p<0.001\end{array}$ \\
\hline
\end{tabular}

Table 2: Mean scores (SD), MANOVA, Bonferroni post hoc and polynomial contrast test results on target variables in three groups.

\section{Intercorrelation between target variables}

Table 3 demonstrates Pearson correlations between the variables using combined data of three groups of participants. The results indicate significant inter-correlations between various variables measured in the present study. There are various inter-correlations between variables. Democratic values are positively correlated with empathy, theory of mind, egalitarian sex role, interpersonal trust, openness, and pro-social behaviour; and negatively associated with normative identity style, suggestibility, and authoritarianism. Moreover, authoritarianism is negatively associated with empathy, theory of mind, interpersonal trust, pro-social behaviour and democratic values; and positively correlated with normative identity style and suggestibility.

\begin{tabular}{|l|l|l|l|l|l|l|l|l|l|l|}
\hline Variables & $\mathbf{1}$ & $\mathbf{2}$ & $\mathbf{3}$ & $\mathbf{4}$ & $\mathbf{5}$ & $\mathbf{6}$ & $\mathbf{7}$ & $\mathbf{8}$ & $\mathbf{9}$ & $\mathbf{1 0}$ \\
\hline Empathy & 1 & & & & & & & & \\
\hline Theory of mind & $0.34^{* *}$ & 1 & & & & & & & \\
\hline Flexibility & 0.08 & $0.15^{*}$ & 1 & & & & & & \\
\hline Egalitarian sex role & $0.22^{* *}$ & $0.17^{*}$ & $0.13^{*}$ & 1 & & & & & \\
\hline Normative identity style & $-0.15^{*}$ & $-0.14^{*}$ & $-0.16^{*}$ & -0.08 & 1 & & & & \\
\hline Interpersonal Trust & $0.16^{*}$ & 0.11 & $0.23^{* *}$ & 0.1 & $-0.23^{* *}$ & 1 & & & & \\
\hline
\end{tabular}


Page 5 of 6

\begin{tabular}{|c|c|c|c|c|c|c|c|c|c|c|}
\hline Openness & $0.30^{* *}$ & $0.33^{* *}$ & 0.11 & $0.20^{* *}$ & $-0.44^{* *}$ & $0.28^{* *}$ & 1 & & & \\
\hline Suggestibility & -0.05 & -0.03 & -0.06 & -0.1 & $0.40^{* *}$ & $-0.22^{* *}$ & $-0.37^{* *}$ & 1 & & \\
\hline Prosocial behaviour & $0.22^{* *}$ & $0.20^{* *}$ & -0.04 & 0.08 & $-0.31^{* *}$ & $0.21^{* *}$ & $0.34^{*}$ & $-0.19^{*}$ & 1 & \\
\hline Authoritarianism & $-0.23^{\star *}$ & $-0.19^{*}$ & 0.11 & -0.09 & $0.48^{\star *}$ & $-0.18^{*}$ & $-0.43^{* *}$ & $0.28^{* *}$ & $-0.21^{* *}$ & 1 \\
\hline Democratic values & $0.29^{* *}$ & $0.29^{* *}$ & 0.11 & $0.21^{* *}$ & $-0.31^{* *}$ & $0.12^{*}$ & $0.57^{* *}$ & $-0.44^{\star *}$ & $0.18^{* *}$ & $* *$ \\
\hline
\end{tabular}

Table 3: Inter-correlations of variables on combined data $(n=376)$.

\section{Discussion}

This research detects the potential differences on psychological and socio-political variables among three samples with distinct cultural backgrounds, i.e., Iranian (new-comers to the UK), bicultural Iranians living in the UK and the British. The results show that bicultural participants scored between two other groups on the measured variables. More specifically, they were higher than Iranian new-comers and lower than their British counterparts on empathy, theory of mind, interpersonal trust, openness, prosocial behaviour, and adherence to democratic values; whilst were lower than Iranian new-comers and higher than the British sample on normative identity style, suggestibility, and authoritarianism. The between-two cultures' findings of bicultural group might be explained by social learning through political socialization.

Cultural tendency and norms are accommodated through socialization from early stage of development [26]. In other words, children are exposed to various cultural norms by agents of socialization, e.g. family, school, peers, and the media $[11,8,10,9]$. One could assume that political values and orientations (among others) would be absorbed by members of a society through social learning and socialization since early childhood. As this is a long-life process, the acquired values and norms will be consolidated in later developmental stages [27]. As Hanson [26] stressed, early life acquisition of new values and norms create a situation in which one can survive migration. Migrant children are raised in family with a cultural background probably different from that of the host society on the one hand, and learn the new cultural values and norms through their daily contacts with for instance school and the mass media. The tendency to maintain the original culture might be perceived by the host society as threatening which, in turn, put pressure on migrants to assimilate or integrate with the dominant host culture [28].

Furthermore, the findings show that there exist positive correlations between adherence to democratic values with empathy, theory of mind, egalitarian sex role, interpersonal trust, openness, and prosocial behaviour; and negative correlations with normative identity style, suggestibility, and authoritarianism. This replicates our previous research findings [3]. These findings have a potential to contribute to knowledge of the links between personality and social characteristics on the one hand and adherence to democratic values on the other hand. These relationships are assumed to enhance our insight into cultural and psychological correlates of democracy.

We also found a main gender effect on empathy showing that women (regardless of the group) tended to be more empathic than to men, that is further supported by t-test results. It is evidently in consistent with previous research findings $[29,14]$. In addition, the present findings, in line with previous studies $[3,2]$ demonstrate a positive association between empathy and support for democratic values, it is expected to see women to be more acceptant of democratic values than men, the fact that Miklikowska [2] found in her study showing that female participants were more supportive of democratic values than their male counterparts.

\section{Conclusion}

The findings point to several social implications and the possibility to inform education system and the media. The results of the present study have significant educational and social implications. Development and maintenance of democracy entails both installation of democratic institutions and presence of democratic citizens; the latter would be a subject for education system to focus on. As emphasized by Niemi and Junn [30] civic educational system would lead to enhancement of democratic values among users. Educational curricula of this kind would be well informed by the present results on psychological underpinnings of democracy. The media, as pivotal agent in public education, can also benefit from present findings.

It should be acknowledged, however, that the findings may not be generalizable to the wider populations who may hold a more traditional views and values. Students are likely to reflect the traits and values inherent in culture and, as such, will provide valuable insight into these issues. Therefore, our target sample in future study will be general population.

\section{Acknowledgement}

For financial support, which made this research possible, the author would like to thank Leverhulme Funds granted through British Academy. We are grateful to British Iranian Community Development Organization (BICTO) for their help in sampling and data collection. Pers Individ Dif

\section{References}

1. Cooper JM (1997) Plato: Complete works. Indianapolis: Hackett.

2. Miklikovaska M (2012) Psychological underpinnings of democracy: Empathy, authoritarianism, self-esteem, interpersonal trust, normative identity style, and openness to experience as predictors of support for democracy. Pers Individ Dif 53: 603-608.

3. Kaviani H, Kinman G (2001) Potential linkage between psychosocial characteristics and socio-political tendencies: A cross-cultural study. J Cross-Cult Psychol.

4. Adorno T W, Frenkel-Brunswick E, Levinson D J, Sanford R (1950) The authoritarian personality. Harper, New York. 
Citation: Kaviani H, Kinman G and Salavat M (2017) Bicultural Iranians Political Tendency: In Between Two Cultures. J Socialomics 6: 206. doi:

Page 6 of 6

5. Greenstein FI (1965) Personality and political socialization: The theories of authoritarian and democratic character. Ann Am Acad Pol Soc Sci 361: 81-95.

6. Matteson LK, McGue M, Iacono WG (2013) Shared environmental influences on personality: A combined twin and adoption approach Behav Genet 43: 491-504.

7. Bandura A (1977) Social learning theory. Englewood Cliffs, Prentice Hall, NJ.

8. Jennings KM (2002) Generation units and the student protest movement in the United States: An intra- and intergenerational analysis. Political Psychology 23: 303-324.

9. Westholm A (1999) The perceptual pathway: Tracing the mechanisms of political value transfer across generations. Political Psychology 20: 525-551.

10. Smith TB, Roberts RN (1995) Acceptance of ethnic groups and perceived attitudes of parents and peers. Percept Mot Skills 2: 80: 370.

11. Campbell D (2008) Voice in the classroom: How an open classroom climate fosters political engagement among adolescents. Political Behaviour 30:437-454.

12. Schoon I, Cheng H (2011) Determinants of political trust: A lifetime learning model. Dev Psychol 47: 619-631.

13. Gibson JL, Duch RM, Tedin KL (1992) Democratic values and transformation of the Soviet Union. J. Polit 54: 329-371.

14. Viterna J, Fallon KM (2008) Democratization, women's movements, and gender-equitable states: A framework for comparison. Am Sociol Rev 73: 668-689.

15. Spreng RN, McKinnon MC, Mar RA, Levine B (2009) The Toronto Empathy Questionnaire: Scale development and initial validation of a factor-analytic solution to multiple empathy measures. J Pers Assess 9: 62-71.

16. Kotov RI, Bellman SB, Watson DB (2010) Multidimensional Iowa Suggestibility Scale (MISS)-Brief Manual.
17. Suzuki A (1991) Egalitarian sex role attitudes: Scale development and comparison of American and Japanese Women. Sex Roles 24: 245-259.

18. Lee K, Ashton MC (2008) The HEXACO personality factors in the indigenous personality lexicons of English and 11 other languages. : J. Personal 76: 1001-1053.

19. Davis MH (1983) Measuring individual differences in empathy: Evidence for a multi- dimensional approach. : J Pers Soc Psychol 44: 113-126.

20. Costa PT, McCrae RR (1992) Revised NEO Personality Inventory (NEOPI-R) and NEO Five-Factor Inventory (NEO-FFI) professional manual. Odessa, FL: Psychological Assessment Resources.

21. Haghshenas H (1999) Normative data on NEO (Revised Form) in an Iranian sample. Thought \& Behaviour 16: 38-47.

22. Berzonsky MD, Soenens B, Luyckx K, Goossens L, Dunkel CS, et al. (2011) Development and validation of the Revised Identity Style Inventory (ISI-4): Factor structure, reliability, and convergent validity.

23. Rotter JB (1967) A new scale for the measurement of interpersonal trust. J. Personal 35: 651-665.

24. Rushton JP, Chrisjohn RD, Fekken GC (1981) The altruistic personality and the self-report altruism scale. Pers Individ Dif 2: 293-302.

25. Zakrisson I (2005) Construction of a short version of the Right-Wing Authoritarianism (RWA) scale. Pers Individ Dif 39: 863-872.

26. Hanson RL (1992) The Political Acculturation of Migrants in the American States. The Western Political Quarterly 45: 355-383.

27. Berry JW (1997) Immigration, acculturation, and adaptation. Applied Psychology: An International Review 46: 5-68.

28. Hindriks P, Verkuyten M, Coenders M (2015) The evaluation of immigrants' political acculturation strategies. International Journal of Intercultural Relations (IJIR) 47: 131-142.

29. Eisenberg N, Lennon R (1983) Sex differences in empathy and related capacities. Psychological Bulletin 94: 100-131.

30. Niemi RG, Junn J (1998) Civic education: What makes students learn. New Heaven: Yale University Press, New York. 